\title{
Swimming in Ireland: Immersions in therapeutic blue space
}

\author{
Ronan Foley ${ }^{1}$ \\ Department of Geography, Maynooth University, Maynooth, Co. Kildare, Ireland
}

\section{A R T I C L E I N F O}

\section{Keywords:}

Swimming

NRT

Blue space

Therapeutic landscapes

Ireland

\begin{abstract}
A B S T R A C T
This paper explores swimming as a healthy body-water engagement in blue space at selected outdoor Irish swimming spots. Associated theoretical underpinnings draw from non-representational theories (NRT). Taking as a starting point the idea of immersion, the paper argues for a deeper application of NRT to blue space settings. In addition, the paper reflects recent therapeutic geographies research on differential experiences of health and wellbeing linked to such immersions. Methodologically, the paper uses observer participation and swimmer's own voices to draw affective and embodied accounts from on and within water. The act of swimming as an emplaced and performed therapeutic encounter is highlighted along with a more critical discussion of contested narratives associated with risk and respect. Theoretical learning suggests the need for greater attention to the production of affect from across the life-course and a fuller articulation of the in-betweenness of theory and empirical testimonies. Swimming emerges from the study as a potentially valuable health and wellbeing resource that can be more fully harnessed to inform wider public health policy.
\end{abstract}

(c) 2014 Elsevier Ltd. All rights reserved.

\section{Introduction: Immersion, water and space}

Swimming, and other forms of immersion in natural waterbodies, have long histories as therapeutic acts within blue space, both in antiquity, through the development of 18th century seaside spas, and in more contemporary narratives around outdoor swimming (Corbin, 1994; Deakin, 2000; Parr, 2011)². Such narratives have traditionally been associated with hydrotherapies and sports and exercise science, with measurable physiological benefits of swimming - in both cold and warm water - well-established components of public and private health policies and behaviours (Chase et al., 2008; Asbullby et al., 2013). In addition, swimming locations or places have wide cultural and emotional resonance and are intriguing examples of what we might conceptualise as therapeutic blue spaces, where water and sky are components of a wider environment producing health and wellbeing (White et al., 2010; Völker and Kistemann, 2011, 2013). In relation to wider health policy, the concept of therapeutic blue space draws from, yet complements existing literatures on the very active promotion of green spaces as environments for healthy living (Depledge and Bird, 2009; Mitchell, 2013).

\footnotetext{
E-mail address: ronan.foley@nuim.ie

1 Tel.: + 35317086024

${ }^{2}$ It cannot be ignored that most contemporary swimming takes place in indoor and private pools, but this paper will focus on swimming in more natural outdoor
} environments.
This paper is concerned with less explicitly measurable, but more qualitatively expressed dimensions of swimming as a healthy activity. It uses a therapeutic landscapes framework in conjunction with emergent theoretical thinking within medical/health geography, specifically around non-representational theories (NRT) (Lorimer, 2008; Andrews et al., 2014). As a linked set of ideas drawn from wider cultural theory, NRT, with their concerns with pre-cognitive processes, embodiment and affect, explores the often ineffable everyday aspects of living in place (Game and Metcalfe, 2011; Anderson, 2014). Connecting such theoretical ideas directly with the act of swimming, itself a visibly non-representational practice, lie at the heart of the paper. At the same time, NRT concerns increasingly overlap with recent writing on therapeutic landscapes, including empirical studies associated with water (Collins and Kearns, 2007, Williams, 2007; Author, 2010, 2011; Foley, 2010, 2011; Wheeler et al., 2012). Recent critical writing from therapeutic geographies argue that place is experienced differently by different people and it is necessary to be mindful of differential therapeutic outcomes at all times (Conradson, 2005). This is especially the case with swimming, simultaneously capable of being joyful, open and healing, yet risky, terrifying and unhealthy (Collins and Kearns, 2007).

To date there has been little research on swimming based on its specific immersive and therapeutic components (Author, 2010; Game and Metcalfe, 2011). The idea of immersion draws on phenomenological concerns, updated within NRT, with personplace interactions and the specific relations between bodies, practices and multi-sensual environments, where surround- 
sounds, touch, and proprioception have explicitly embodied dimensions (Lorimer, 2008; Andrews et al., 2014). Research on coastal landscapes identifies therapeutic potentials around immersion, though these tend to be more contemplative, based on views of water (Wylie, 2005; White et al., 2010; Ryan, 2012). This paper argues for a need to stretch this a little and 'jump in', both literally and litorally. In so doing, and in uncovering narratives and responses from the water, a better understanding of swimmers' motivations and psychologies may extend conceptions of health and blue space practice in public health terms. Interestingly, much global public health policy associated with swimming is understandably focused on risk and safety (World Health Organisation (WHO), 2006). I suggest however, that it may be important to counterbalance this in more positive ways; mindful of the voices of swimmers themselves, who respect the water, but are drawn to it for the emotional and physical supports it provides (Collins and Kearns, 2007; White et al., 2010; Parr, 2011).

The primary aim of this work positions swimming as a means to develop theoretical engagements within therapeutic landscapes research, specifically in the growing research area of blue space. In so doing, a number of additional objectives are identified, namely a critical assessment of swimming as; a potentially healing act, expressed in swimmer's own accounts; as a development of NRT and lived everyday health geographies, and as a development of Conradson's (2005) notion of differential and contested healing outcomes in place.

\section{NRT, affect and therapeutic geographies}

The theoretical frameworks that inform this paper are those of NRT or, reflecting the ongoing importance of traditional representation, more-than-representational theories (Lorimer, 2008; Thrift, 2008; Ryan, 2012). Within medical and health geographies, the use of NRT have been slowly making ground, if not always explicitly. There is a useful summary in Andrews et al. (2014) recent Canadian paper that documents how NRT have become more influential in the subject. Citing Cadman (2009), they identify NRT as having three theoretical antecedents, phenomenology, neovitalism, and post-structuralism. The first two are of specific interest to this research, as they reflect a concern for person-environment interactions with lived and active components (Harrison, 2008; Thrift, 2008). NRT seek to theorise everyday lives and practices beyond a purely representative take; and consider how place itself is produced through every-day practices and performances (Cadman, 2009). NRT are especially interested in the role of the body and its affective responses in, to and from place. These are not necessarily neutral agentive acts, unshaped by wider living structures and contexts, but have autonomy and expressive, felt and sensual realities of their own (Tolia-Kelly, 2006; Anderson, 2014). Cresswell (2012) notes that much NRT writing is theoretically dense and less commonly illustrated by empirical clarification. In part this reflects particular NRT methodological concerns that are resistant to being overly empirical, where interpretation, explanation and analysis of everyday acts, by definition, convert them into representational modes (Gregg and Seigworth, 2010). One might wonder how else one can describe and make sense of the seemingly inexplicable, though it's worth noting that even foundational geographical writing on NRT, such as Thrift (1997) and McCormack's (2002) work on dance, have recognisably material emplacements.

Bearing this in mind, and teasing out more fully this theoreticalempirical tension in NRT, debates on affect and emotion are a good starting point, though people sometimes use the terms interchangeably (Thien, 2005; Anderson, 2014). Affect is variously invoked as a body's capacity to act or be acted on and as a bodily becoming that pre-structures codified emotional responses to physical experiences (Dewsbury, 2003). Such philosophical definitions, avowedly distanced from concretised explanations or interpretations of everyday practice and encounter (such as feeling/ emotion), have been critiqued for a contradictory abstraction that makes their utilisation in grounded research difficult (Thien, 2005; Tolia-Kelly, 2006). Andrews et al. (2014) suggest that NRT, considered in health and wellbeing terms, are loose enough to allow such tensions so that, 'the key non-representational idea of 'affect' is employed as a study framework, indicating how wellbeing arises initially as an energy and intensity through the physical interaction of human bodies and non-human objects, and is experienced as a feeling state' (Andrews et al., 2014, 211). Affect can be better seen as a form of mobile energy between people and things, encompassing a wide range of often inexpressible felt sensations. They illustrate this through auto-ethnographic descriptions of playing in water and teaching children to swim in the summertime in Canada, with the text invoking the 'slip-slop' of the sound of water or the 'boomboom-cha' of music that becomes part of experiential place encounters that encompasses others (relational) and are acted out in open-ended environments (processual). Such instinctive and precognitive components (central to affect debates) are co-produced by and in place. In this case, both individual and associated place energies are causally linked to heat and light and even the kinaesthetics of place-encounters. One can argue, especially when applied to swimming, that energies are stored up in and emerge from across the life-courses as well. They are essentially embodied in that sense, from received wisdoms and knowledges (how to swim, what not to do), but also through childhood and adult experiences that shape subsequent pre-cognitive feelings and memories and personal-place echoes (Ryan, 2012). In the author's case this might be reflected in a near-drowning experience in waves as a four-year old, or through a family history of repeated visits to seaside locations. NRT have traditionally had a greater focus on the individual moment and while it does consider cumulative affects, it might be extended to consider multiple moments stored in bodyplace memories and how they shape affective encounters (Anderson, 2009).

Extending this discussion to aspects of active embodiment, similar discussions on affect (as latent sense) and feeling/emotion (as material expression) are identifiable (Spinney, 2006; Game and Metcalfe, 2011; Ryan. 2012). Affect, perched between anticipation and subsequent entry into action, is inherently latent until one lets go, both physically and mentally. Spinney, in an auto-ethnographic study of cycling up the long steep climb of Mont Ventoux in France, evokes place image and memory (its history as a Tour de France climb and shrine) but also his own kinaesthetic struggles with heat and aching muscles to express the inexpressible affects of the experience. For him movement and the coalescence of subject (cyclist) and object (bike), are enacted in a complex relational space to uncover an identifiably 'pre-representational' practice; 'the character of the ascent is brought to life not just by describing a landscape visually but by describing the sensations of moving through it', p724. Such thinking can be easily extended to swimming where body-subject within water-object are equally framed by affect, memory and context. Game and Metcalfe (2011) identify that same sense of movement and kinaesthetic response to and in place on Bondi Beach in Sydney. The respondents; walkers, joggers and swimmers, describe their activities in almost archetypal forms, and the authors note, 'it is everyday recreation that takes them out of their subjective and human-centred emotional states into the spatial-temporal depths of the relational state of "well-being". In particular they draw on Bachelard's idea of being in 'felicitous' (blue) space that opens up affective healing possibilities, linked to recovery and restoration, identifiable in references to the beach as 'Dr. Bondi'. 
As noted in the introduction, greater attention has been paid to a more critical stance on the assumed therapeutic benefits of place (Williams, 2007). This is in part informed by experiential aspects of NRT and also by wider cultural geographical concerns with difference. The work of Conradson $(2005,2007)$ in particular, has moved the subject into a more forceful engagement with what he calls 'differential imbrications', experiences linked to immersion in place. Based on research in UK retreat settings, he notes that the same place affects different people in different ways and that one cannot always assume either a therapeutic outcome or that the extent of such effects would be the same for all. In linked research, Collins and Kearns (2007) examined the empirical setting of the beach in New Zealand for its potential wellbeing effects and identified positive outcomes, including well-being, exercise and being out in blue space components of sky and water. Yet simultaneously, in the exposed fresh-air and seas, drowning and melanomas were identifiable 'risk' elements in that same environment, that produced distinctly unhealthy outcomes for others in that same space. Here a sense of openness often used as a positive aspect of NRT thinking can also give rise, in more grounded spaces, to an exposure to risk. While discourses of risk are prominent within wider new public health discourses (Beck, 1992; World Health Organisation (WHO), 2006), Harrison's (2008) discussion of (corporeal) vulnerability, taps more thoughtfully into wider discourses around risk and difference that challenges assumptions on active embodied engagements in other ways. He argues for a consideration of the passive within the active, especially for people suffering from pain, injury and disability.

In combining NRT with ongoing research on contested therapeutic geographies, I situate the work to more closely uncover the affective potentials of active therapeutic encounters in blue space (Rose, 2012). I see it meeting at a sort of interface - like the uncertain shoreline spaces it describes - between theoretical discussions on affect/emotion and the body and on active swimming subjects-where potential health outcomes, as visible processes and engagements, individual and collective, emerge from a specific setting and practice. Such encounters in blue space are potentially felicitous but may also have uncertain, even negative and unhealthy outcomes for active body-subjects. Conradson and Latham (2007) suggest that certain places attain reputations for providing 'affective possibilities', and this reputational power has been a foundational trope within therapeutic landscapes research (Gesler, 2003). Because of this identity, blue spaces become focal points for individuals who value them and seek them out, with a 'feeling for the coast' acting as centripetal force for both lifestyle and wellbeing, but also through lifelong affinities to place-based spatial experiences (Kearns and Collins, 2012; Ryan, 2012).

\section{Method}

The research is drawn from a wider oral historical study of coastal and inland swimming spots (as swimming locations are often referred to) in Ireland. The historical context and social and cultural histories of individual locations form part of that wider narrative, and this paper draws from two particular locations, the 40 Foot $^{3}$ just outside Dublin and the Guillemene in County Waterford. Both are quite theatrical settings, their approaches and surrounds being framed by rocks and cliffs but with extensive viewing and dressing areas, with everyday use across the year, though more intensively used in Summer (Fig. 1). Each has steps into the water, are 'swimmable' in any tide, have additional sitting

${ }^{3}$ The 40 Foot is named either after an old Military Regiment who were stationed at the site, or the depth of the water at mean tide. and diving rocks as well as informal built environments of shelters, club rooms, stone seats and railings. An important additional consideration is that this paper is based on sea-swimming in a cold water climate, but with commentaries applicable to other types of global blue space including; rivers, lakes, springs and artificial forms (such as reservoirs and quarries).

The research methodology incorporated a mix of observer participation and responses from swimmers, informed by NRT methods that focus on a witnessing that 'aims to generate data infused with a fidelity or authenticity to happenings, relaying as much as possible of their character and action' (Andrews et al., 2014, 213). The research was ethically cleared and I have to date carried out interviews with twenty different swimmers, with core empirical material drawn from four specific accounts. The interviews were conducted through an oral history approach, which encouraged an open life-course narrative of the swimmer's life, that for this paper, draws from the more health and place oriented content. In addition, commentaries from secondary sources, including newspapers, radio interviews and social media pages contextualise the sites as presented to a wider public. I also carried out observer participation at the two sites from 2012 to 2014. The sites were visited at different daylight hours (depending on the season), an hour at a time, to get a sense of how the spaces themselves were conducive to affective and healthy encounters. In addition, the ethnographic approach uncovered evidence of a wide range of swimming performances by multiple bodies - arrival, dressing, swims of mixed duration and post swim recovery and conversation - that in turn made a wide range of non-representational knowledge more visible, audible and perceptible.

The oral historical approach was also informed by the idea of life-course testimony, using interviews that were deliberately open-ended, but also contained some semi-structured prompts to tease out evidence on emotional and affective responses to swimming. Such prompts included asking about their early swimming, their swimming communities, choices and preferences for swimming locations, the feelings that swimming engendered and whether health and wellbeing fitted in their narrative, if at all? It should be critically noted that swimming itself, especially when discussed with everyday swimmers, can be banal, and certainly there was a degree of agreement across many accounts that did not provide explicitly useful evidence. But the choice of method gave space to swimmers to consider the subject differently than they would normally, with a large proportion of subjects noting they had never really thought about it (swimming) in such a way before. Anderson (2014), commenting on surfing, an associated form of water-body engagement, saw part of the challenge of NRT's supposed non-representability, as not so much exploring what we didn't know, as communicating meaningfully what we do. For example, the notion of the wave is well known to both swimmers and surfers and comes back to the idea of energy. The wave, or for swimmers, the swell of the sea, are he posits, kinetic energy given material form. To immerse oneself in those swells opens up a relational sensibility where one can show as well as tell. Such themes strongly underpin the choice of approach used in this research.

The thematic discussion is built on the three methods used; participant observation, secondary reporting and representative primary voices. The first two are deliberately lightly used with the bulk of the commentary drawn from the primary material. The empirical discussion uses two broad themes that extend the literature; immersive therapeutic practices and outcomes and affect, embodiment and emotion within blue space. The first argues for a therapeutic geography that emerges from within the practice and setting, in this case swimming within blue space, while the second emplaces those wider theoretical concepts within an empirical setting and takes a strong evidence-based 

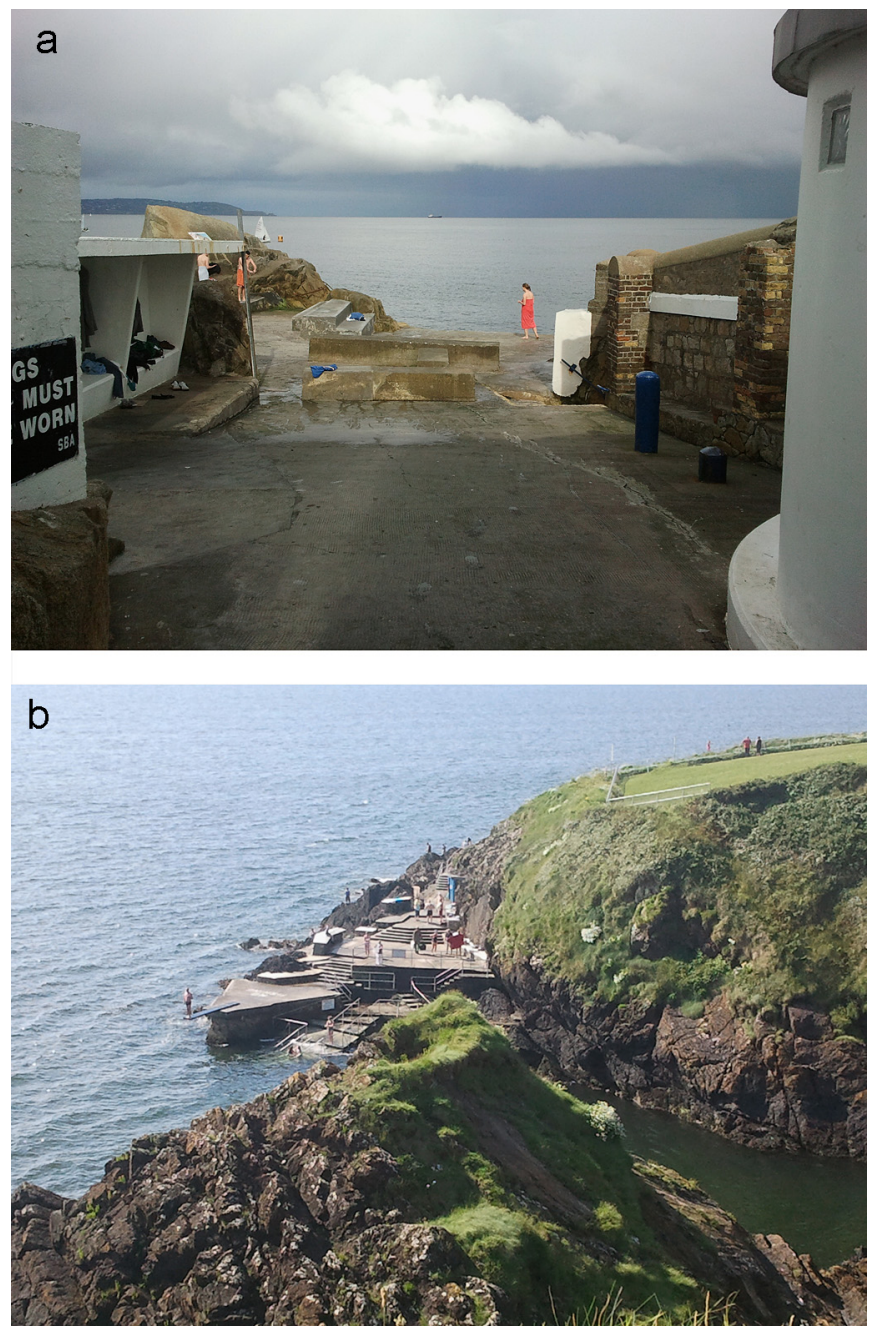

Fig. 1. The 40 Foot Dublin and the Guillemene, Tramore, Co. Waterford. Source: Author.

approach to how those themes are articulated. In summarising the responses, a number of additional themes emerged that bear comment, especially in relation to NRT thinking, around rhythm, fluidity and specifically place-based affects. While some of the evidence used suggests a preference for wellbeing over risk narratives, the paper does acknowledge the permanent risk of swimming in the uncontrolled open water. As noted by Philip Hoare (pers. comm.), 'the sea is never your friend'.

\section{Swimming in therapeutic blue space}

\subsection{Immersive therapeutic practices and outcomes}

At both sites, immersion practices were evident in a wide number of forms. From participant observation notes at the Guillemene on August 18th, 2013, place performance opened up a veritable assemblage of activity (Anderson, 2009);

The fine summer's day seems to have brought out all sorts. Young children tentatively jump from the diving board under supervision from anxious yet proud parents (Fig. 2). Older teenage boys, dive from crude diving stones into the water with a vigorous thunk, depending on size and weight. They are not especially good swimmers, being content to doggy-paddle back to the dive zone. Most of the children wear light wetsuits.

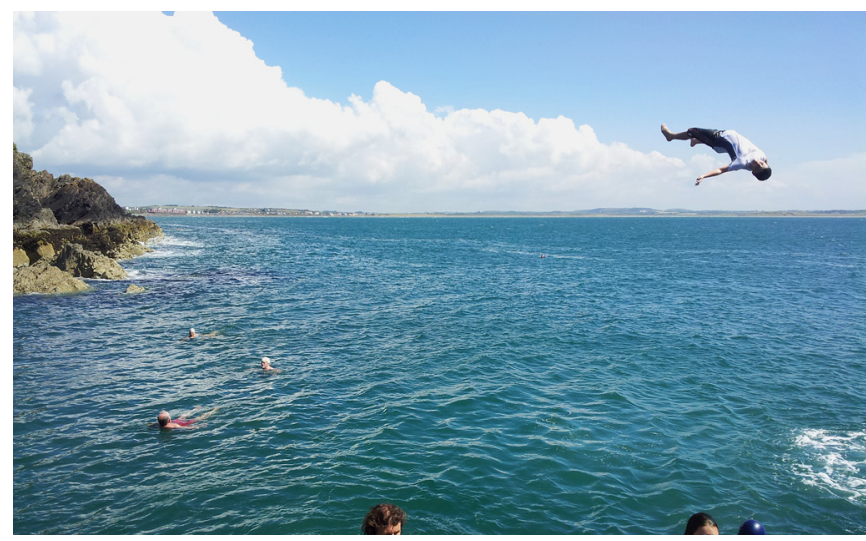

Fig. 2. Swimming practices at the Guillemene, Summer 2013. Source: Author.

Older adults take more leisurely swims in the swell, content to look around them; happily moving at their own speed. They tend to be dressed in togs. An old man, too frail to get in to the water, brings a bucket so he can at least douse himself in the fresh sea-water, a process he calls a 'shower of freshness'.

In this snapshot, we can identify a range of physical forms of immersion that are in a sense communal, but within which individual variations emerge. The vigour of the impact with the water depends on size, age, gender and whether it is an autonomous or supervised act. Yet it is a free engagement, in a sense beyond interpretation; stored within the swimmers themselves and the immediacy of their water-air encounter. For swimmers, a feeling for place and process are intertwined and often hard to explain, though an understood openness adds to the power of the encounter;

I love water and I love being in water and I love the fact that you've got all the space around you. That's funny, because you've got the whole expanse when you're in the 40 Foot; out to sea across the bay. I suppose it's just a good feeling, and in the summer it's wonderful, you know yourself, it just therapeutic I think (Respondent M. 40 Foot).

In addition, specific therapeutic benefits are identified or perceived by respondents. Swimming has historically been identified as having active benefits in terms of the treatment of a range of specific chronic conditions, such as rheumatism, arthritis and skin conditions (Author, 2010). Respondent T (Guillemene) stated in a fairly typical comment, 'Since I started coming here around ten years ago, the arthritis in my legs has gone away, and I think it's the swimming that does that'. Other comments focus on aspects of strength and fitness at different stages of a swimmer's life, though one always performed in a felicitous space.

I've been aware of it just for building up my own strength and fitness levels. I need to go back to swimming. For me that's a kind of priority for the next while. Not going down the 40 Foot, I tend to miss the kind of atmosphere, the camaraderie, that sense of going somewhere. I remember one of the guys saying, of course you are (missing it), you're home. (Respondent N. 40 Foot).

While the attachment to place and practice is important to swimmers, there is also a very clear and inbuilt sense of both fear and respect for the environment in which they find themselves, that suggests a finer attunement to risk (Collins and Kearns, 2007), and a recognition of being in an environment that is both known and utterly unknown. 
I like having the company ... if you are going somewhere way out of your depth ... you need to have somebody around you just to know that they are there if you need (them). But usually if I swim in that area, you're out of your depth anyhow, so you're in an unknown territory. So you have this inbuilt sense of, what I feel one should have, of fear. It doesn't have to mean frightened, but its respect because you are in an environment that isn't yours; so you've always got to be mindful of that (Respondent Y. 40 Foot).

In addition, the risks inherent in diving into water represent, on one level, a joyful embodied act, but on another, a risky activity which raises questions of personal and place safety. A swimmer, born and brought up nearby described diving at the Guillemene site; Surrounding cliff faces carry mini-diving platforms at a variety of heights. From a young age I was warned to dive out-the most important safety message for any swimmer there' (Irish Times, 2012). Here an awareness of danger, shaped by site topographies, was ingrained early in the swimmer's psyche, a place of affective and anticipatory storage (Thrift, 2008).

Identifiable healing outcomes also emerge from accounts that, while acknowledging potential benefits, do not do so entirely uncritically. There is a counter-intuitiveness to swimming in cold water on cold days, especially when one has a cold. Respondents monitor their swimming in a way that reflects their personal understanding of their own health status. As they note, it doesn't always work and at times, the cold becomes an active deterrent as both affective force and potential health risk.

It's just an interesting thing about swimming. Even in the winter, even if you think you have a cold, you think it will help, even if it doesn't always work (Respondent M. 40 Foot).

Now the cold water is a different matter sometimes that can make you very cold. I stopped swimming for a while cause I started getting very chilled, cold and stopped enjoying it in the same way (Respondent N. 40 Foot).

Other aspects of health that emerge at the sites include illness recovery, in relation to both physical and mental health. One respondent noted that the 40 Foot is a site commonly used for fund raising for several medical charities, with a particular interested in breast cancer (Fig. 3). Reflecting work by Grace (2012) on Dragonboat racing in Devon as a form of illness recovery in blue space, swimming has reportedly become an important part of recovery regimes for breast cancer suffers at the site. In addition, the value for swimming for the recovery of mental health, also emerged from a respondent's comments on swimmers she knew;

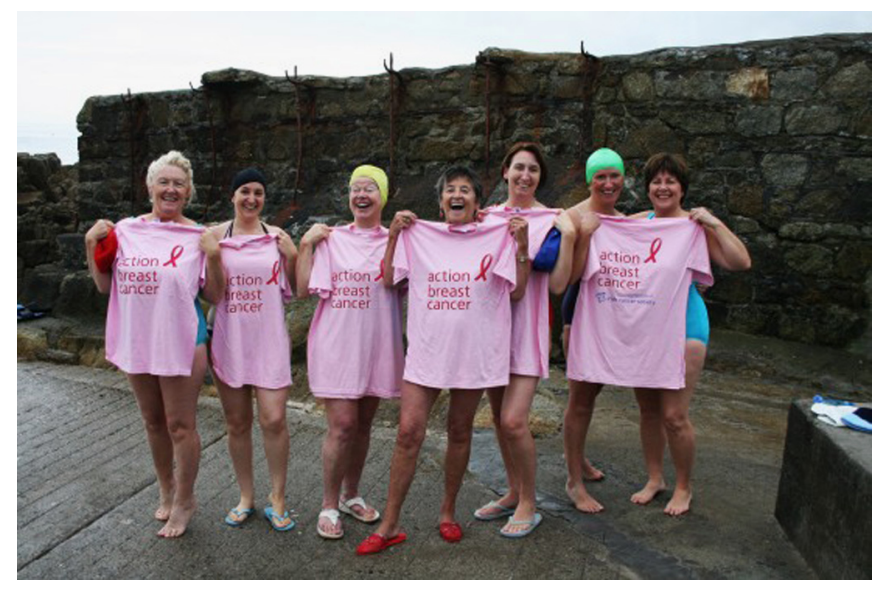

Fig. 3. Breast cancer fundraiser at the 40 Foot in 2009. Source: http://fortyfootthe movie.com/the-fundraiser/fund-raiser-photos/.
Well I do know quite a few people who swim at the 40 Foot who have sort of mental illness ... depressions really and quite a few of those people say they find swimming really beneficial. They often come down and swim and come out and don't really engage or talk to other people and some of the others say, oh they're unfriendly or a bit odd. But I think that's fine. I do talk to one person I know and they say they just like to go into the water and it's like a little rest or a treatment for them (Respondent Y. 40 Foot).

\subsection{Affect, embodiment and emotion in blue space}

Affect, embodiment and emotion remain at the heart of NRT. As noted above, theoretical writing creates a clear distinction between affect, as something instinctive, kinetic, pre-cognitive and emotion/feeling as more concrete, even representational forms of knowing (Anderson, 2014). In a sense the respondents reflect the difficulties of articulating the space between affect and emotion. A common response was how hard it was 'to explain' the actions and feelings of swimming. From an observer-participant perspective, the following described a swim at the 40 Foot in early September, 2012, that mirrors an earlier comment on feeling a little 'out-of-place' in the water.

I make my usual hesitant entry into the water down the steps. It's one body part at a time, anticipating the cold on the more vulnerable bits - goolies (testicles), chest, shoulders - but I get in more quickly than usual. I stick by head in the water and swim around 15 crawl strokes out and stop. Lifting my head out of the water and looking back at land, I see swimmers and spectators, and a slight subtle sense of panic, something old, as my mind and body adjusts to being out of its depth. I'm a little unsure of my place, but slowly my body, and I am grateful for the extra bit of blubber I am carrying, begins to adjust to the water temperature and my place perception returns.

Swimmers are equally caught in this in-betweenness of affect, emotion and the body and reflect instinctively on this in a nonrepresentational way (Gregg and Seigworth, 2010). In attempting to describe the affective encounter, there are also implicit references to wellbeing as an ineffable, even cumulative experiential outcome. The interplay of the words affect and effect reflect this often confusing discourse, but one with an empowering value, as reflected in the act of swimming as an energiser against more difficult aspect of daily living;

It's some indefinable thing especially if you swim all the year round. It just has some kind of effect. I couldn't even begin to describe it to be honest with you, but it has got an effect on you which ... it's hard to explain, it just makes you feel better about the day ahead. That you can sort of deal with stuff in a sense. (Respondent M. 40 Foot).

An additional dimension of affect as discussed in the literature is the idea of a subject-place rhythm, invoked in settings like cycling and the coast (Spinney, 2006; Ryan, 2012). As noted previously, there is an evident unpredictable rhythm in coastal tidal water, especially at the 40 Foot, where the biggest swells come from backwash from Irish Sea ferries. As Seigworth and Gregg (2010) note, 'affective environments can therefore be thought of as the taking place of these force-encounters, as the happening of the ebbs and swells of intensities ... passing between bodies'. Such wave-like rhythms and intensities also relate to the different groups of swimmers who inhabit the 40 Foot, with a rhythm across time and space created by more communal organic inhabitations; 
It goes through phases and there are sort of waves of people. Different groups have different rhythms. I used to swim with the 11 o'clock group, but it varies. People fall off and other people join and I suppose in that sense the groups change and they nearly have a sort of life of their own (Respondent N. 40 Foot).

A more nuanced understanding of affect, as the active experience of a becoming subject (Thien, 2005) is evident in several comments. While situated on the more interpretative side of the affect-emotion divide (perhaps in Lorimer's terms, more-thanemotional) it reflects on senses of buoyancy and weightlessness;

I love it (swimming). It makes me feel very complete or something; very relaxed. It's quite ... buoyant actually. I love the sensation of weightlessness and the kind of speed and momentum you can get up in the water. There's a kind of a playful element to it as well I love (Respondent N. 40 Foot).

Perhaps the following best exemplifies an affective account of swimming at the 40 Foot, where embodied rhythm is uncovered in practice, and emerges as an unforeseen and almost indescribable form of becoming within the water. Here Bachelard's identification of a felicitous space encounter is evident in a simultaneous engagement of several bodily senses and a lingering impact recalling other past and future moments as well (Game and Metcalfe, 2011). Such an affective response would not and could not be identifiable without the experience of it.

But also when I am swimming along on my own, especially in the summertime, I have to say I enjoy it more. You just go into this lovely rhythm. I suppose it's a bit like meditating. You just go into this calm state and you listen to your breathing and you visualise your body and what it's doing with each stroke. And if there's a slight wave you just become aware sort of, of your arm falling at a different ... falling into the water you know ... touching the water at a different ... you were expecting and oh ... in your head you reach it at the top of a wave and in fact you reach it at the bottom and it's very difficult to explain. It's just like you listen to your body, that's rather nice (Respondent Y. 40 Foot).

NRT have at their heart a concern, not just with everyday practice, but also with how bodies engage in and with place, and how this in turn provides an experiential slant on 'being-in-thewater'. For many swimmers that embodied experience is quite personal and individual yet, in Strang's (2004) words, simultaneously typical and unique. The act of swimming is for some a habit and compulsion, for others 'not an obsession' but bodily responses to the water are often contingent and unpredictable, based on personal, communal and place moods and even the time of day or year. For one of the 40 Foot respondents;

I never used to swim unless the sun was shining, it was very hot and there was no wind. And then about 8 years ago I must have been here swimming in the summer and I thought everyone else is kind of carrying on so why don't I and I did and I got through the winter. I did it I think, most of the winter and it's amazing how a habit ... if you do something every day you can't even miss a day. Cause if you miss a day you feel ... why did I miss today? You do feel a guilt if you don't go down. That's what a lot of the swimmer's say. It's not a chore but it's just something that becomes so much part of your daily routine that you just don't want to miss it. And even if you go down and you think oh my god it's too wet and its windy and its horrible ... and then suddenly you get in and it's mad. And it is mad and it's not just me who says that-the others will say that as well. It's a compulsion, it actually a compulsion. (Respondent M. 40 Foot).

For another the felt response in place was expressed as a timespecific, almost unconscious body happiness;

Yeah, usually the middle of the day. My body time is from about 12 to 3 (laughs) ... I've tried swimming in the morning, didn't do anything for me. It's like my best time. I'll dip if I feel I have to at other times, but, yeah my body is happy in the middle of the day swimming (Respondent Y. 40 Foot).

More broadly, the relationship between the swimmer and the body emerged as a sort of internal embodiment, developed almost incrementally through familial and place proximity to the sea. From an NRT perspective, pre-cognitive aspects of both affect and practice/performance are inbuilt in swimmers, giving a habitual practice a deeper life-long instinct (Ryan, 2012). Another respondent from the Guillemene, hinted at a certain powerlessness and even a lack of control in swimming that they found soothed their body. This passing nod to stress relief, suggests that there are counter values in finding a place to literally let the body go, and open-water swimming provides this.

I think it's probably part of me, and equally my family. I think we just ... it's very difficult ... I suppose it's something so basic and its ingrained and it's there from nearly birth and becomes part of what you are as well. (Respondent Y. 40 Foot).

Frequently, the quiet heave of rising and falling water is a small indicator of a powerful sea on which you float like a crumb in a bath (Irish Times, 2012).

\section{Discussion}

As a specific consideration around theory and empirical evidence, I have considered Andrews et al. (2014) question as to, 'how might embodied experiences of movement in affective encounters be related to health and wellbeing?' For the respondents, the relationship between more embodied forms of affect, worked out in place was, in keeping with NRT sensibilities, an emergent one. It was emergent across the life course, with an early respect for the sea and its dangers mentioned by most respondents; an affective response inscribed early into their psyches that could be visceral and embodied,

We lived beside the sea between Derry and Buncrana and the first thing we were taught to do was learn to swim because there were very dangerous currents there. When I was about 5 or 6 my father taught me how to swim. I can't remember (how) but it was probably immersion-total immersion (mimics being dropped in), i.e., this is what happens if you don't swim. (Respondent Y. 40 Foot)

All of the accounts above are from outdoor swimming spaces, and it is the case that such swimmers are a minority nationally, where young children are more likely to learn in indoor pools and leisure centres. Discussions with indoor swimmers, beyond the scope of this work, might identify a completely opposite set of responses, where comfort, safety, reliability and calmness were preferred to the discomfort, risky unpredictability and wildness of the sea. For some outdoor swimmers, swimming in a pool was preferable to not swimming at all, though others identified such spaces as uninteresting. In part this was to do with the artificial and non-natural nature of such spaces, characterised by chlorine and an oppressive atmosphere. For others it was precisely because of the 'straight-line' predictably of the encounter and the more open possibilities of the sea; 
Now it has to be sea water. Never liked swimming in a pool. You have to swim in a straight line. If you are in the sea, even if you think you are swimming in a straight line, you're never swimming in a straight line (Respondent Y. 40 Foot).

Here the swimmer's response emphasises the importance of the more natural blue space of open water (as opposed to the more simulated blue of the indoor pool) and the less restricted movement in that place.

NRT's concerns with emergent practices and processes are identifiable in the places as well as the people. Of especially interest to an NRT perspective, is the blue space of the sea itself. This is a space that is mobile and fluid, is governed by its own processes and in turn re-acts on the people who immerse themselves in it. Wider discussions on what Hoare (2013) describes as 'the sea inside' also suggest that human bodies are made up of considerable amounts of water, typically $55-60 \%$ depending on age that, he argues, provide affects of a pre-dispositional type. The comment below identifies that the sea is different every day, but so are we and our bodies. This aspect of the continual processing of an active yet ageing body in its own currents, might also figure more prominently in non-representational thinking.

The thing to remember is that every time you get into the sea, the sea is different to what it was the day before, it's never the same sea that you get into. If you go more or less at the same time the tide will be an hour higher or lower. It could still be calm, but there'll be a current going in or out and that will change. So every day you get into the sea it's different. (Respondent Y. 40 Foot).

\section{Conclusion}

Andrews et al. (2014) argue that non-representational theory can uncover, 'how the well comes into being' and I would argue that swimming as a wellbeing component of everyday life has a co-productive geography from and of blue space. While none of the empirical responses explicitly mention the term, the centrality of the sea and the sky/air around it are deeply implicated. From the visual and performative aspects of the observer participation, a sense of other forms of showing as well as telling also emerge (Anderson, 2014). In relation to the telling, almost all of the respondents find the swimming experience, despite its everyday status, as being quite 'difficult' to verbalise. Yet in the words they choose, and the descriptions of an affective sense of what they intuit, feel, enact and respond to in the water, they do find often eloquent means to show their experiences. Words like atmosphere and freshness come up in some of those hesitant accounts that encapsulate a sense of a non-representational emergence where action, place and beneficial outcomes meet (Anderson, 2009; McCormack, 2010). Such words are often impossible to explain but we get it, from the context, the known action, our own experiential memories and emotions.

The paper argues for an application of NRT to a therapeutic activity in blue space in a number of ways; firstly by using swimming, an activity central to blue space thinking and secondly exploring this from a critical theoretical framework that blends therapeutic geographies and NRT to tease out a specific value of affect to wellbeing. Swimming, according to the Irish respondents, mostly affects them in positive ways, though a respect for the dangers of the water is also affectively-present. NRT are extended into a new empirical environment, in which we can identify a set of processes that are anticipatory, immersive and reflective and that take place before, during and after the activity. These are not momentary acts in isolation, and the importance of a life-course engagement with swimming in a range of relational places is potentially significant for health and wellbeing. Here the relational refers to family histories, but also, linking back to older phenomenological thinking, networked individual and communal swimming lifeworlds across time and space (Seamon, 1979; Cadman, 2009).

This paper has touched only briefly on a range of subjects and there is considerable room for wider research around swimming, health and wellbeing. These can be focused into three broad strands of study. First, and in line with therapeutic geographies concerns with contestable outcomes, further research might explore differentiated accounts from swimmers and swimming spaces. The different ways in which children, teenagers, younger and older adults and even the very elderly, swim for health purposes, opens up huge space for inter-generational work in generally inter-generational spaces, using a range of qualitative methodologies (Spinney, 2006). The potential for example, to use waterproof recording devices in the water, capturing affective and embodied senses in situ, might prove invaluable. Several of the respondents also reference the unique smells, tastes and feel of the water, from which additional sensual blue-scapes may be uncovered. In addition, such work might usefully engage with three contesting groups, those who can't, don't and won't swim. These may be for cultural, social (see Wiltse, 2007 on contested AfricanAmerican swimming histories) or personal traumatic reasons all of which might challenge the assumed benefits of swimming in different ways (Davidson and Parr, 2007).

As a second linked strand, the sometimes contested co-performing emplacement of healthy and unhealthy bodies together has huge potential, already explored in feminist and fat activism research (Evans, 2010). Swimming is a great leveller and can at times transform the unhealthy land body into a healthy sea-body (Throsby, 2013). This opens up space for a potentially rich exploration of health outcomes enacted by bodies of difference. Methodological initiatives, drawn from a more active NRT framing, may also uncover narratives from a range of such informants such as cancer survivors (Grace, 2012). The UK-based Blue Gym project uses quantitative analyses drawn from health psychology to more explicitly measure the potential value of blue space encounters to inform health policy (White et al., 2010). Though this paper has focused on the qualitative, a two-pronged approach might capture both bio- and social medical attention and do no harm in strengthening evidence bases for the value of swimming.

Finally, associated components of NRT only mentioned in passing, such as non-human geographies, also provide space for the subject to grow. The role of technologies (noted in passing) such as wet-suits, goggles, neoprene boots and hats, all allow swimmers to extend their therapeutic encounters in the water. While there is a tendency for outdoor swimmers to eschew such technologies, they can and do promote swimming and its curative potential, especially in colder latitudes. Clearly none of this applies in warmer latitudes of the Mediterranean or Caribbean where sea swimming may be a normal non-exceptional encounter, though one that most narratives still frame as joyful and healing (Lenček and Bosker, 1998). Finally, a fuller discussion around the wider place assemblages of swimming may also extend the range of settings, many of which are neither blue nor healthy, used in empirical research. The image of the teenage boy leaping into water is a global trope, visible in often idyllic blue space, yet also enacted in frankly dangerous polluted settings such as the Ganges at Varanasi (Naskar, 2014). Methodologically such images tell a thousand stories and capture, whatever the risk, an affective, instinctive, non-representational act that has a worldwide resonance for human health and wellbeing.

\section{References}

Anderson, B., 2009. Affective atmospheres. Emot. Space Soc. 2 (2), 77-81. Anderson, J., 2014. Exploring the space between words and meaning: understanding the relational sensibility of surf spaces. Emot. Space Soc. 10, 27-34. 
Andrews, G., Chen, S., Myers, S., 2014. The 'taking place' of health and wellbeing: towards non-representational theory. Soc. Sci. Med. 108, 210-222.

Asbullby, K., Pahl, S., Webley, P, White, M., 2013. The beach as a setting for families' health promotion: a qualitative study with parents and children living in coastal regions in Southwest England. Health Place 23, 138-147.

Author, 2010. Details Removed for Peer Review.

Author, 2011. Details Removed for Peer Review.

Beck, U., 1992. Risk Society: Towards a New Modernity. Sage, London.

Cadman, L., 2009. Nonrepresentational theory/nonrepresentational geographies. In: Kitchin, R., Thrift, N. (Eds.), International Encyclopedia of Human Geography. Elsevier, London.

Chase, N., Sui, X, Blair, S., 2008. Swimming and all-cause mortality risk compared with running, walking, and sedentary habits in men. Int. J. Aquat. Res. Educ. 2 (3), 213-223.

Collins, D., Kearns, R., 2007. Ambiguous landscapes: Sun, risk and recreation on New Zealand beaches. In: Williams, A. (Ed.), Therapeutic Landscapes. Ashgate, Farnham, pp. 15-32.

Conradson, D., 2005. Landscape, care and the relational self: therapeutic encounters in rural England. Health Place 11, 337-348.

Conradson, D., 2007. The experiential economy of stillness: places of retreat in contemporary Britain. In: Williams, A. (Ed.), Therapeutic Landscapes. Ashgate, Farnham, pp. 33-48.

Conradson, D., Latham, A., 2007. The affective possibilities of London: antipodean transnationals and the overseas experience. Mobilities 2 (2), 231-254.

Corbin, A., 1994. The Lure of the Sea. The Discovery of the Seaside in the Western World. Polity Press, Cambridge, pp. 1750-1840.

Cresswell, T., 2012. Geographical Thought: A Critical Introduction. Wiley-Blackwell London.

Davidson, J., Parr, H., 2007. Anxious subjectivities and spaces of care: therapeutic geographies of the UK National Phobics Society. In: Williams, A. (Ed.) Therapeutic Landscapes. Ashgate, Farnham, pp. 95-110.

Deakin, R., 2000. Waterlog: A Swimmer's Journey Through Britain. Vintage, London.

Depledge, M., Bird, W.J., 2009. The Blue Gym: health and wellbeing from our coasts. Mar. Pollut. Bull. 58, 947-948.

Dewsbury, J.-D., 2003. Witnessing space: 'knowledge without contemplation'. Environ. Plann. A 35, 1907-1932.

Evans, B., 2010. Anticipating fatness: childhood, affect and the pre-emptive 'war on obesity'. TIBG 35, 21-38.

Foley, R., 2010. Healing Waters: Therapeutic landscapes in historic and contemporary Ireland. Ashgate, Farnham.

Foley, R., 2011. Performing health in place: The holy well as a therapeutic assemblage. Health Place 17, 470-479.

Game, A., Metcalfe, A., 2011. 'My corner of the world': Bachelard and Bondi beach. Emot. Space Soc. 4, 42-50.

Gesler, W.M., 2003. Healing Places. Rowman \& Littlefield, Lanham.

Grace, M., 2012. Geography, Cancer and Dragon Boats: Ethnographic Explorations of Breast Cancer Dragon Boating in the Lake District, UK (Unpublished Ph.D. Thesis). University of Exeter.

The Affect Theory Reader. In: Gregg, M., Seigworth, G. (Eds.), Duke University Press, Durham NC.

Harrison, P., 2008. Corporeal remains: vulnerability, proximity, and living on after the end of the world. Environ. Plann. D 40 (2), 423-445.

Hoare, P., 2013. The Sea Inside, London. Fourth Estate.

Kearns, R., Collins, D., 2012. Feeling for the coast: the place of emotion in resistance to residential development. Soc. Cult. Geogr. 13 (8), 937-955.
Lenček, L., Bosker, G., 1998. The Beach. The History of Paradise on Earth. Secker \& Warburg, London.

Lorimer, H., 2008. Cultural geography: non-representational conditions and concerns. Prog. Hum. Geogr. 32, 551-559.

McCormack, D., 2010. Fieldworking with atmospheric bodies. Perform. Res. 15 (4), 40-48.

McCormack, D.P., 2002. A paper with an interest in rhythm. Geoforum 33 (4), 469-485.

Mitchell, R., 2013. Is physical activity in natural environments better for mental health than physical activity in other environments? Soc. Sci. Med. 91, 130-134.

Naskar, S., 2014. The river where swimming lessons can be a health hazard (last accessed, July 1st, 2014). BBC News Mag. online 〈http://www.bbc.com/news/ magazine-28112403〉.

Parr, S., 2011. The Story of Swimming. Dewi Lewis, Stockport.

Rose, E., 2012. Encountering place: a psychoanalytic approach for understanding how therapeutic landscapes benefit health and wellbeing. Health Place 18, 1381-1387.

Ryan, A., 2012. Where Land Meets Sea: Coastal Explorations of Landscape, Representation and Spatial Experience. Ashgate, Farnham.

Seamon, D., 1979. A Geography of the Lifeworld. Croom Helm, London.

Seigworth, G., Gregg, M., 2010. An inventory of shimmers. In: Gregg, M., Seigworth, G. (Eds.), The Affect Theory Reader. Duke University Press, Durham, pp. 1-28.

Spinney, J., 2006. A place of sense: a kinaesthetic ethnography of cyclists on Mont Ventoux. Environ. Plann. D 24, 709-732.

Strang, V., 2004. The Meaning of Water. Berg, Oxford.

Thien, D., 2005. After or beyond feeling: a consideration of affect and emotion in geography. Area 37 (4), 450-456.

Thrift, N., 1997. The still point: expressive embodiment and dance. In: Pile, S., Keith, M (Eds.), Geographies of Resistance. Routledge, London, pp. 124-151.

Thrift, N., 2008. Non-Representational Theory. Space/Politics/Affect. Routledge, London.

Throsby, K., 2013. 'If I go in like a cranky sea lion, I come out like a smiling dolphin': marathon swimming and the unexpected pleasures of being a body in water. Feminist Rev. 103, 5-22.

Irish Times, 2012. Wild about water. Special section on wild swimming (August 2nd, 2012). Irish Times.

Tolia-Kelly, D., 2006. Affect-an ethnocentrist encounter? Exploring the 'universalist' imperative of emotional/affectual geographies. Area 38 (2), 213-217.

Völker, S., Kistemann, T., 2011. The impact of blue space on human health and wellbeing-Salutogenetic health effects of inland surface waters: a review. Int J. Hyg. Environ. Health 214, 449-460.

Völker, S., Kistemann, T., 2013. “I'm always entirely happy when I'm here!” Urban blue enhancing human health and well-being in Cologne and Düsseldorf, Germany. Soc. Sci. Med. 78, 113-124.

Wheeler, B., White, M., Stahl-Timmins, W., Depledge, M., 2012. Does living by the coast improve health and wellbeing? Health Place 18, 1198-1201.

White, M., Smith, A., Humphreys, K., Pahl, S, Snelling, D., Depledge, M., 2010. Blue Space: the importance of water for preference, affect, and restorativeness ratings of natural and built scenes. J. Environ. Psychol. 30, 482-493.

Therapeutic Landscapes. In: Williams, A. (Ed.), 2007. Ashgate, Farnham.

Wiltse, J., 2007. Contested Waters. A Social History of Swimming Pools in America. University of North Carolina Press, Chapel Hill.

World Health Organisation (WHO), 2006. Guidelines for Safe Recreational Water Environments.Volume 2: Swimming Pools and Similar. WHO, Geneva.

Wylie, J., 2005. A single day's walking: narrating self and landscape on the South West Coast Path. TIBG 30 (2), 234-247. 